\title{
Ultraviolet B (UVB) Induces Down-regulation of Parkin Gene Expression
}

\author{
Sung Hoon Kim ${ }^{1,8}$, Yeo Wool Kang ${ }^{1,8}$, Juyeon Lee ${ }^{2}$, Hyun-Kyung Kim ${ }^{1,3}$, \\ Byung Chul Jung ${ }^{1}$, Bohee Kim ${ }^{1}$, Dai Joong Kim ${ }^{4}$ and Yoon Suk Kim ${ }^{1, \dagger}$ \\ ${ }^{l}$ Department of Biomedical Laboratory Science, College of Health Sciences, \\ Yonsei University, Wonju, Gangwon-do 26493, Korea \\ ${ }^{2}$ Scientific Investigation Division, Seoul Metropolitan Police Agency, Jongno-gu, Seoul 03169, Korea \\ ${ }^{3}$ Department of Biomedical Laboratory Science, College of Natural Science, \\ Gimcheon University, Gimcheon, Gyungbuk 39528, Korea \\ ${ }^{4}$ Department of Laboratory Medicine, Bundang Jesaeng General Hospital, \\ Sungnam, Kyonggi-do 13590, Korea
}

\begin{abstract}
Ultraviolet (UV) irradiation induces cellular damage. A variety of cellular responses for repairing cellular damage including DNA damage occur after UV irradiation. During the repair processes, expression and activation of various molecules are regulated depending on the types of cellular damage. Parkin is an E3 ligase and act as a tumor suppressor. Recently, it has been reported that Parkin is involved in the DNA repair process. In the current study, we investigated whether UVB irradiation influences expression of Parkin. Parkin expression transiently decreased after UVB irradiation both at the mRNA and protein levels, but returned to normal levels thereafter. Taken together with cell viability data, Parkin expression is down-regulated during UVB-induced suppression of cell growth and is increased again in accordance with recovery of UVB-induced cell growth inhibition. However, Parkin overexpression or knockdown did not influence UVB-induced cell growth inhibition and recovery. We propose that Parkin could be a useful molecular marker for evaluating conditions of cells after UVB irradiation.
\end{abstract}

Key Words: Ultraviolet B, Parkin, Cellular damage, Biomarker

\section{INTRODUCTION}

Ultraviolet (UV) is a constituent of sunlight and is divided into three components according to its wavelength: UVA (314 400 nm), UVB (280 315 nm) and UVC (190 280 $\mathrm{nm}$ ) (Schuch et al., 2013). UV irradiation is a cause of cellular damage and leads to DNA damage (Lindahl and Barnes, 2000; Jackson and Bartek, 2009; Yagura et al., 2011).
Cells exposed to UV initiate various signal pathways (Xu and Fisher, 2005). UV irradiation regulates cell cycle regulatory proteins which results in cell cycle arrest in the G1-S phase/G2-M phase for repairing cellular damage (Pearce and Humphrey, 2001; Branzei and Foiani, 2008; Asimuddin and Jamil, 2012). It has been reported UV irradiation activates ataxia telangiectasia mutated and $\operatorname{Rad} 3$ related (ATR) (Branzei and Foiani, 2008). Rad1 and Rad17 are also known to be activated in response to UV irradiation (Pearce

\footnotetext{
*Received: March 22, 2016 / Revised: March 30, 2016 / Accepted: March 30, 2016

$\S$ These authors contributed equally to this manuscript

† Corresponding author: Yoon Suk Kim. Department of Biomedical Laboratory Science College of Health Sciences, Yonsei University Wonju 26493, Korea. Tel: +82-33-760-2860, Fax:+82-33-760-2195, e-mail: yoonsukkim@yonsei.ac.kr

(C) The Korean Society for Biomedical Laboratory Sciences. All rights reserved.

(C) This is an Open Access article distributed under the terms of the Creative Commons Attribution Non-Commercial License (http://creativecommons.org/licenses/by-nc/3.0/) which permits unrestricted non-commercial use, distribution, and reproduction in any medium, provided the original work is properly cited.
} 
and Humphrey, 2001). Further, it has been reported that UV irradiation stimulates a variety of molecules including cell cycle checkpoint kinase 1 (Chk1), Chk2, and p53 (McGowan, 2002; Asimuddin and Jamil, 2012) and induces accumulation of p21 (CDK) (Abraham, 2001). In addition, cell growth inhibition, cell cycle transition, senescence and apoptosis can occur immediately after exposure to UV irradiation for repairing damage (Lombard et al., 2005; Jackson and Bartek, 2009). During these repair processes, different repair molecules are activated according to the type of damage (Sancar et al., 2004).

Parkin is an E3 ligase and its mutation is primarily known as a cause of autosomal recessive Parkinson's disease. Loss of function mutations of Parkin leads to accumulation of $\alpha$-synuclein and it causes neuronal cell death (Yasuda and Mochizuki, 2010). Several reports have proposed that Parkin functions as a tumor suppressor in cancer cells (Tay et al., 2010). Recently, it has been reported that Parkin participates in the repair process induced by DNA damage. Parkin was demonstrated to bind with proliferating cell nuclear antigen (PCNA) and promote repair of UV-induced damage (Kao, 2009b). Another report showed that UV irradiation induces nuclear translocation of Parkin and interaction of translocated Parkin with damaged DNA suggesting that Parkin reduces UVB-induced DNA damage (Kao, 2009a). However, the exact function of Parkin as a repair molecule in response to UV irradiation was not fully understood. Based on the reports described above, in the present study, we examined implication of Parkin in UVB-induced cell growth suppression and recovery. We found that UVB irradiation regulates Parkin expression both at the mRNA and protein levels. We suggest that Pakrin is a useful marker for evaluating conditions of cells after UVB irradiation.

\section{MATERIALS AND METHODS}

\section{Materials}

Dulbecco's modified Eagle's medium (DMEM), fetal bovine serum (FBS), penicillin-streptomycin, trypsin-EDTA, and trypan blue stain solution were purchased from Gibco BRL (Grand Island, NY, USA). Trizol reagent, random hexamers, and Moloney Murine Leukemia Virus Reverse
Transcriptase (MMLV-RT) were purchased from Invitrogen (Grand Island, NY, USA). Antibody against $\beta$-actin was purchased from Santa Cruz Biotechnology (Santa Cruz, CA, USA). Antibody against Parkin was purchased from Abcam Technology (Cambridge, MA, UK). Recombinant adenoviral vector including Parkin gene (Parkin virus) was produced as previously described by Kim et al. (Kim et al., 2006).

\section{Cell culture}

HEK293 (Human embryonic kidney epithelial cells, ATCC) was grown in DMEM supplemented with 10\% FBS and streptomycin-penicillin. Cells were maintained at $37^{\circ} \mathrm{C}$ in a humidified atmosphere with $5 \% \mathrm{CO}_{2}$.

\section{Ultraviolet (UV) irradiation}

HEK293 cells were seeded into 6-well plates $\left(2 \times 10^{5}\right.$ cells / well) and cultured in 10\% FBS DMEM. After $24 \mathrm{~h}$, growth medium was replaced with PBS and cells were irradiated with UVB (312 nm) using a UV cross linker (Westbury, NY, USA). The PBS was replaced with $10 \%$ FBS DMEM and cells were cultured until analyzed.

\section{Trypan blue dye exclusion assay}

Cells were trypsinized with trypsin-EDTA (500 $\mu \mathrm{l} /$ well) for $1 \mathrm{~min}$ and then neutralized with 10\% FBS-DMEM (1.5 $\mathrm{ml})$. The collected cell suspension was mixed with trypan blue stain solution and non-stained cells (viable) were enumerated using a hematocytometer (Marienfeld, Germany).

\section{Reverse transcriptase-polymerase chain reaction (RT- PCR)}

Total RNA was extracted from cells and cDNA was synthesized as previously described (Lim et al., 2014). PCR analysis of individual cDNA was performed using specific primers and $0.2 \mathrm{U}$ of Taq polymerase (Genetbio, Nonsan, Chungnam, Korea) in a thermocycler. The PCR primer sequences were as follows: Parkin; forward 5'-GGA GGC GAC GAC CCC AGA AAC-3'; reverse 5'-GGG ACA GCC AGC CAC ACA AGG-3', GAPDH; forward 5'-CGG GAA GCT TGT CAT CAA TGG-3'; reverse 5'-CGC AGT GAT GGC ATG GAC TG-3'. Amplified PCR products were separated on $1.5 \%$ agarose gels. Gel images were obtained 
with a Gel Doc instrument (Bio-Rad, Hercules, CA, USA).

\section{Western blot assay}

The protein loading samples were prepared and subjected to Western blot as previously described (Lee et al., 2015). Proteins were separated by SDS-PAGE and transferred to nitrocellulose membranes (Pall, Mexico). Protein blots were incubated with primary antibody overnight at $4{ }^{\circ} \mathrm{C}$. Each immunoblot was incubated with the appropriate horseradish peroxidase-labeled secondary antibody (anti-mouse or antirabbit). Immune-labeled proteins were detected using an ECL kit (Thermo, USA) and X-ray film (AGPA, Belguim). A $\beta$-actin antibody was used as an internal control.

\section{Parkin gene overexpression}

HEK293 cells were seeded into 6-well plates $\left(1 \times 10^{5}\right.$ cells / well) and infected with Parkin and Mock virus (1 M.O.I) for $90 \mathrm{~min}$ in serum-free DMEM. After $90 \mathrm{~min}$, fresh medium containing FBS were added and cells were maintained for further analysis.

\section{Small interfering RNA (siRNA) transfection}

HEK293 cells $\left(1 \times 10^{5}\right.$ cells / well $)$ were seeded into 6-well plates. After $24 \mathrm{~h}$, siRNA was transfected. Prior to transfection, siRNAs were mixed with Liposome in serumfree DMEM. Cultured medium was removed and siRNALiposome mixture was added to cells. After $4 \mathrm{~h}$, transfected cells were supplemented with fresh medium containing FBS. The siRNA sequences were as follows: siRNA specific for Parkin; sense 5'-GCA CCU GAU CGC AAC AAA UTT-3', antisense 5'-AUU UGU UGC GAU CAG GUG CTT-3', non-specific siRNA; sense 5'-AUG AAC GUG AAU UGC UCA ATT-3', antisense 5'-UUG AGC AAU UCA CGU UCA UTT-3'. siNS (non-specific siRNA) was used as a universal control.

\section{RESULTS AND DISCUSSION}

\section{UVB irradiation induces transient suppression of cell growth}

We reported previously that UVB transiently suppresses proliferation of HEK293 cell (Lee et al., 2015). In this study,

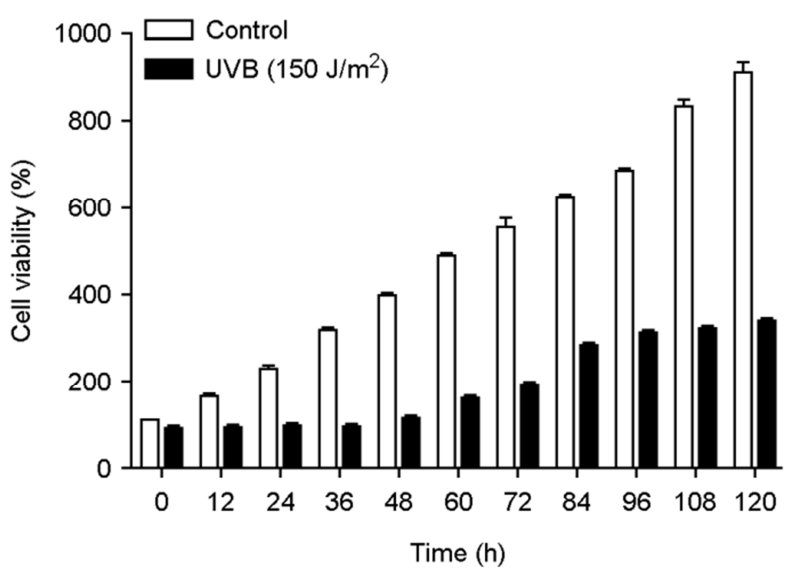

Fig. 1. UVB irradiation transiently suppresses cell proliferation. HEK 293 cells were treated with $150 \mathrm{~J} / \mathrm{m}^{2}$ of UVB and incubated for the indicated times, then viable cells were enumerated by trypan blue dye exclusion assay. The control group (control) indicates non UVB-treated cells. The numbers of viable cells at $0 \mathrm{~h}$ in the control group was set as $100 \%$. Data are expressed as the mean \pm SEM from three independent experiments.

we first reconfirmed whether cellular proliferation was suppressed by UVB irradiation. Compared to non-irradiated control cells, proliferation of cells was suppressed beginning at $12 \mathrm{~h}$ after $150 \mathrm{~J} / \mathrm{m}^{2}$ of UVB irradiation (Fig. 1). However, the suppression of cell growth was transient and the cells resumed proliferation at $48 \mathrm{~h}$. Based on this result, we reconfirmed that UVB transiently inhibits cell growth.

\section{Expression of Parkin decreased transiently during UVB} induced suppression of cell growth

A variety of molecules are known to participate in cell proliferation in response to UV irradiation resulting in cell growth suppression for repair (Pearce and Humphrey, 2001; Branzei and Foiani, 2008; Asimuddin and Jamil, 2012). Parkin is known to suppress cancer cell growth. Recently, it has been reported that Parkin is involved in repair of UV-induced DNA damage (Kao, 2009b; Kao, 2009a). Based on these reports, we investigated whether Parkin is associated with UVB-induced cellular responses. Cells were irradiated with UVB $\left(100 \mathrm{~J} / \mathrm{m}^{2}\right.$ or $\left.200 \mathrm{~J} / \mathrm{m}^{2}\right)$ and the expression level of Parkin was analyzed both at the mRNA and protein levels by RT-PCR and Western blot assay. As shown in Fig. 2A, mRNA expression of Parkin was reduced within $12 \mathrm{~h}$ 
(A)

$\underline{\text { Control }}$

$\begin{array}{llllllllllll}\text { Time (h) } & 0 & 12 & 24 & 36 & 48 & 60 & 72 & 84 & 96 & 108 & 120\end{array}$

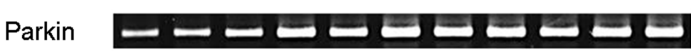

GAPDH

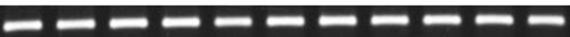

$\underline{\operatorname{UVB}\left(100 \mathrm{~J} / \mathrm{m}^{2}\right)}$

$\begin{array}{llllllllllll}\text { Time (h) } & 0 & 12 & 24 & 36 & 48 & 60 & 72 & 84 & 96 & 108 & 120\end{array}$

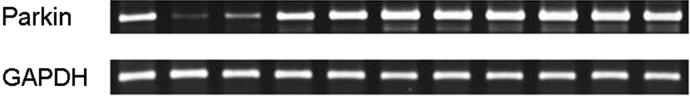

UVB $\left(200 \mathrm{~J} / \mathrm{m}^{2}\right)$

$\begin{array}{llllllllllll}\text { Time (h) } & 0 & 12 & 24 & 36 & 48 & 60 & 72 & 84 & 96 & 108 & 120\end{array}$

Parkin $-\infty-\infty-\infty=0$

GAPDH

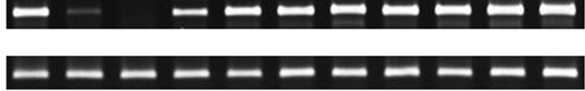

B

\section{$\underline{\text { Control }}$}

$\begin{array}{llllllllllll}\text { Time (h) } & 0 & 12 & 24 & 36 & 48 & 60 & 72 & 84 & 96 & 108 & 120\end{array}$

Parkin

$\beta$-actin

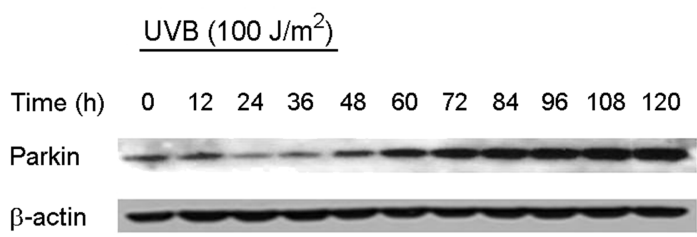

\section{UVB $\left(200 \mathrm{~J} / \mathrm{m}^{2}\right)$}

$\begin{array}{llllllllllll}\text { Time (h) } & 0 & 12 & 24 & 36 & 48 & 60 & 72 & 84 & 96 & 108 & 120\end{array}$

Parkin

$\beta$-actin

Fig. 2. Parkin is transiently down-regulated during UVB-induced cell growth inhibition. HEK293 cells were irradiated with the indicated doses $\left(100\right.$ and $\left.200 \mathrm{~J} / \mathrm{m}^{2}\right)$ of UVB and incubated for the indicated times. Control group (control) indicates non UVB-irradiated cells. (A) Parkin expression at the mRNA level was assayed by RT-PCR. GAPDH was used as an internal control. (B) Expression of Parkin at the protein level was analyzed by Western blot assay. Parkin protein was detected using specific antibody against Parkin. $\beta$-actin was used as an internal control.

but recovered at $36 \mathrm{~h}$ and $48 \mathrm{~h}$ after UBV irradiation in cells treated with $100 \mathrm{~J} / \mathrm{m}^{2}$ and $200 \mathrm{~J} / \mathrm{m}^{2}$ respectively. Protein level of Parkin decreased within $24 \mathrm{~h}$ and $36 \mathrm{~h}$ and recovered at $48 \mathrm{~h}$ and $60 \mathrm{~h}$ after exposure to UVB in cells treated with $100 \mathrm{~J} / \mathrm{m}^{2}$ and $200 \mathrm{~J} / \mathrm{m}^{2}$ of UVB, respectively (Fig. 2B). These results seem to correlate with the kinetics of cell viability by UVB irradiation (Fig. 1). Therefore, Parkin may be associated with UVB-induced cell growth suppression and recovery.

\section{Regulation of Parkin expression does not influence} UVB-induced cell growth inhibition

It has been reported that Parkin suppresses proliferation of cancer cells (Tay et al., 2010) and is implicated in the process of repairing UV-induced damage (Kao, 2009b). In addition, the present study showed that Parkin expression is down-regulated during the period of UVB-induced cell growth inhibition. Based on these reports and our results, we examined whether Parkin is associated with UVB-induced suppression of cellular proliferation. First, to investigate the effect of Parkin overexpression on UVB-induced cell growth inhibition, Parkin was overexpressed in HEK293 cells. Then, the cells were irradiated with UVB and maintained for $24 \mathrm{~h}$. Parkin overexpression was maintained after UVB irradiation (Fig. 3A), but in Parkin-overexpressed and UVB-irradiated cells, there was no noticeable change in cell viability compared to cells irradiated with UVB alone (Fig. 3B). Next, we examined whether knockdown of Parkin expression influences UVB-induced suppression and recovery of cell proliferation. Parkin expression was down-regulated in HEK293 cells using siRNA specific for Parkin (siPK) (Fig. 3C), then the siRNA-transfected cells were treated with UVB. When compared to cells exposed with UVB alone, there were no significant changes in cell viability in siPKtransfected cells after UVB irradiation (Fig. 3D). Taken together, we found that regulation of Parkin expression does not affect UVB-induced suppression and recovery of cell growth. We have yet to definitely determine the exact role of Parkin in UBV-induced cellular responses. It has been reported that UVB induces mitochondria damage (Wang et 
A

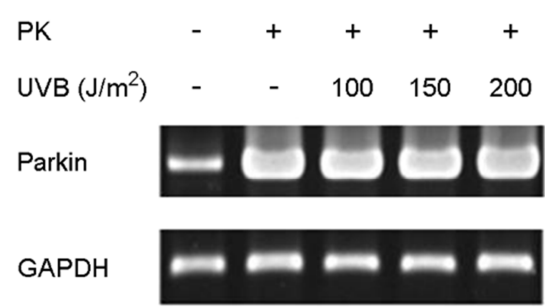

B
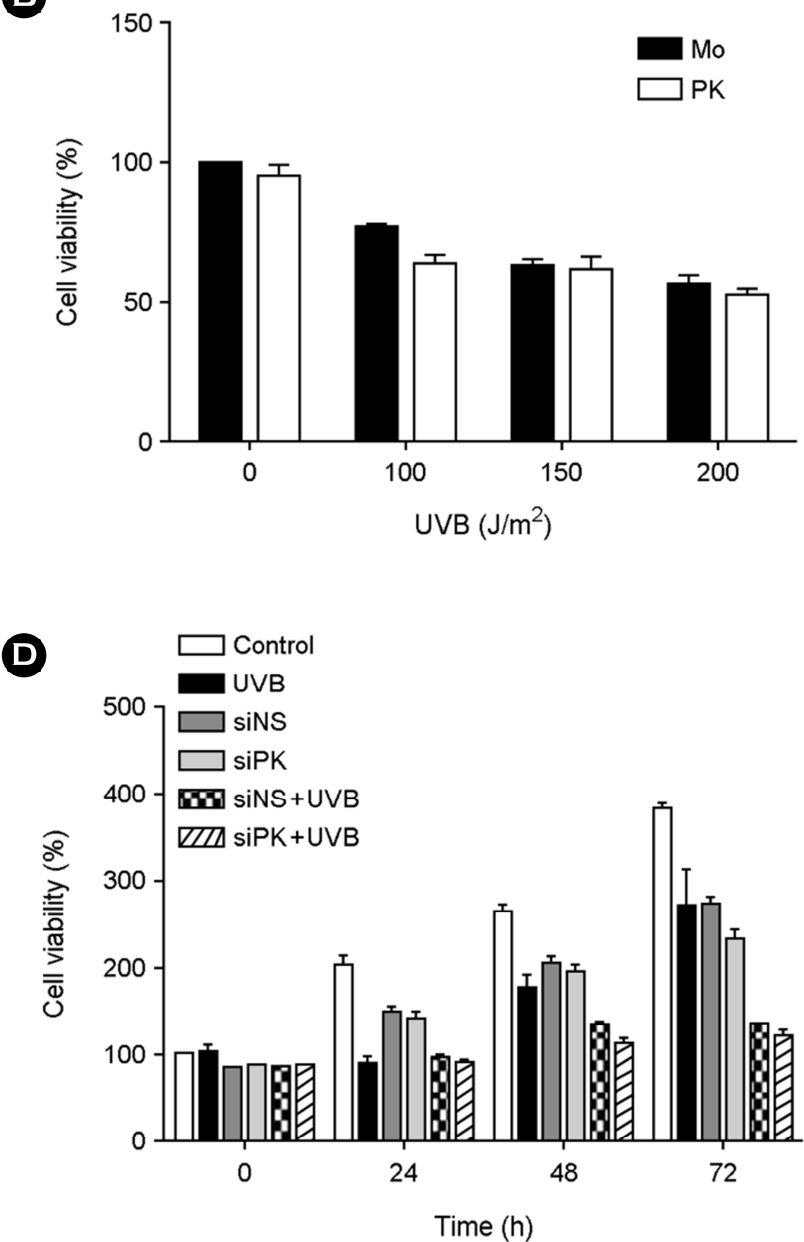

Fig. 3. Parkin does not affect UVB-induced cell growth inhibition. (A) HEK293 cells were infected with 1 M.O.I. Parkin-expressing virus (PK) and incubated for $24 \mathrm{~h}$. The infected cells were irradiated with indicated doses of UVB and maintained for $24 \mathrm{~h}$. Parkin mRNA expression was assayed by RT-PCR. (B) HEK293 cells were infected with 1 M.O.I. Parkin or Mock virus (Mo) for 24 h. The infected cells were irradiated with the indicated doses of UVB and incubated for $24 \mathrm{~h}$. Viable cells were enumerated by trypan blue dye exclusion assay. The numbers of viable cells in non-irradiated and Mock virus infected group was set as $100 \%$. Data were expressed as the mean \pm SEM from three independent experiments. (C) HEK293 cells were transfected with indicated concentrations of siRNA for Parkin (siPK) and $100 \mathrm{nM}$ non-specific RNA (siNS) for $24 \mathrm{~h}$. mRNA expression of Parkin was analyzed by RT-PCR. (D) HEK293 cells were transfected with $100 \mathrm{nM}$ siPK or siNS for $24 \mathrm{~h}$ and irradiated with $150 \mathrm{~J} / \mathrm{m}^{2} \mathrm{UVB}$. The irradiated cells were maintained for indicated times. Viable cells were enumerated by trypan blue dye exclusion assay. The numbers of viable cells in non-irradiated and -infected group was set as $100 \%$. Data were expressed as the mean \pm SEM from three independent experiments. Control (non-infected, non-irradiated group), UVB (non-infected, UVB-irradiated group), siNS (siNS-infected, non-irradiated group), siPK (siPK-infected, non-irradiated group), siNS+UVB (siNS-infected, UVB-irradiated group), siPK+UVB (siPK-infected, UVB-irradiated group).

al., 2003). In addition, Parkin can act as a sensor for mitochondrial damage, becoming recruited to damaged mitochondria to enhance their removal by autophagy (Carroll et al., 2014). Although, future research is needed to elucidate the contribution of Parkin, we suggest that Parkin may be a useful molecular marker for evaluating conditions of cells after UVB irradiation.

\section{Conflict of interest}

The authors declare that they have no conflict of interest.

\section{REFERENCES}

Abraham RT. Cell cycle checkpoint signaling through the ATM and ATR kinases. Gene Dev. 2001. 15: 2177-2196. 
Asimuddin M, Jamil K. Insight into the DNA repair mechanism operating during cell cycle checkpoints in eukaryotic cells. Biology and Medicine. 2012. 4: 147.

Branzei D, Foiani M. Regulation of DNA repair throughout the cell cycle. Nat Rev Mol Cell Bio. 2008. 9: 297-308.

Carroll RG, Hollville E, Martin SJ. Parkin sensitizes toward apoptosis induced by mitochondrial depolarization through promoting degradation of Mcl-1. Cell Rep. 2014. 9: 1538-1553.

Jackson SP, Bartek J. The DNA-damage response in human biology and disease. Nature. 2009. 461: 1071-1078.

Kao SY. DNA damage induces nuclear translocation of parkin. J Biomed Sci. 2009a. 16: 67.

Kao SY. Regulation of DNA repair by parkin. Biochem Bioph Res Co. 2009b. 382: 321-325.

Kim YS, Patel S, Lee SJ. Lack of direct role of parkin in the steady-state level and aggregation of alpha-synuclein and the clearance of pre-formed aggregates. Exp Neurol. 2006. 197: 538-541.

Lee J, Rhee KJ, Kim SH, Kang YW, Cho Y, Yang SJ, Pan CH, Kim YS. O-6-Methylguanine-DNA methyltransferase (MGMT) gene expression is associated with ultraviolet B (UVB)induced cell growth inhibition and recovery. Genes Genom. 2015. 37: 789-796.

Lim J, Kim SH, Kang YW, Jung BC, Kim H-K, Lee J, Lee D, Rhee K-J, Kim YS. Triglyceride up-regulates expression of ABCG1 in PMA-induced THP-1 macrophages through activation of JNK and p38 MAPK pathways. Biomed Sci Lett. 2014. 20: 237-243.

Lindahl T, Barnes DE. Repair of endogenous DNA damage. Cold Spring Harb Symp Quant Biol. 2000. 65: 127-133.

Lombard DB, Chua KF, Mostoslavsky R, Franco S, Gostissa M,
Alt FW. DNA repair, genome stability, and aging. Cell. 2005. 120: 497-512.

McGowan $\mathrm{CH}$. Checking in on Cds1 (Chk2): a checkpoint kinase and tumor suppressor. Bioessays. 2002. 24: 502-511.

Pearce AK, Humphrey TC. Integrating stress-response and cellcycle checkpoint pathways. Trends Cell Biol. 2001. 11: 426 -433 .

Sancar A, Lindsey-Boltz LA, Unsal-Kacmaz K, Linn S. Molecular mechanisms of mammalian DNA repair and the DNA damage checkpoints. Annu Rev Biochem. 2004. 73: 39-85.

Schuch AP, Garcia CCM, Makita K, Menck CFM. DNA damage as a biological sensor for environmental sunlight. Photoch Photobio Sci. 2013. 12: 1259-1272.

Tay SP, Yeo CW, Chai C, Chua PJ, Tan HM, Ang AX, Yip DL, Sung JX, Tan PH, Bay BH, Wong SH, Tang C, Tan JM, Lim KL. Parkin enhances the expression of cyclin-dependent kinase 6 and negatively regulates the proliferation of breast cancer cells. J Biol Chem. 2010. 285: 29231-29238.

Wang CB, Ding BX, Guo SB, Wang YZ, Han YT, Wang YJ. Protective effect of polypeptide from Chlamys farreri on mitochondria in human dermal fibroblasts irradiated by ultraviolet B. Acta Pharmacol Sin. 2003. 24: 692-696.

$\mathrm{Xu}$ YR, Fisher GJ. Ultraviolet (UV) light irradiation induced signal transduction in skin photoaging. J Dermatol Sci. 2005. S1-S8.

Yagura T, Makita K, Yamamoto H, Menck CF, Schuch AP. Biological sensors for solar ultraviolet radiation. Sensors (Basel). 2011. 11: 4277-4294.

Yasuda T, Mochizuki H. The regulatory role of alpha-synuclein and parkin in neuronal cell apoptosis; possible implications for the pathogenesis of Parkinson's disease. Apoptosis. 2010. 15: 1312-1321. 